\title{
Asperosaponin VI promotes angiogenesis and accelerates wound healing in rats via up-regulating HIF-1 $\alpha /$ VEGF signaling
}

\author{
Cheng-gui WANG ${ }^{1,2}$, Yi-ting LOU ${ }^{1,2}$, Min-ji TONG ${ }^{1,2}$, Li-lian ZHANG ${ }^{1,2}$, Zeng-jie ZHANG ${ }^{1,2}$, Yong-zeng FENG ${ }^{1,2}$, Shi LI ${ }^{1,2}$, \\ Hua-zi $\mathrm{XU}^{1,2, *}$, Cong $\mathrm{MAO}^{1,2, *}$ \\ ${ }^{1}$ Department of Orthopedics, the Second Affiliated Hospital and Yuying Children's Hospital of Wenzhou Medical University, Wenzhou \\ 325000, China; ${ }^{2}$ Key Laboratory of Orthopedics of Zhejiang Province, the Second Affiliated Hospital of Wenzhou Medical University, \\ Wenzhou 325000, China
}

\begin{abstract}
Wound therapy remains a clinical challenge due to the complexity of healing pathology and high demand of achieving functional and aesthetically satisfactory scars. Newly formed blood vessels are essential for tissue repair since they can support cells at the wound site with nutrition and oxygen. In this study, we investigated the effects of Asperosaponin VI (ASA VI) isolated from a traditional Chinese medicine, the root of Dipsacus asper Wall, in promoting angiogenesis, as well as its function in wound therapeutics. Treatment of human umbilical vein endothelial cells (HUVECs) with ASA VI $(20-80 \mu \mathrm{g} / \mathrm{mL})$ dose-dependently promoted the proliferation, migration and enhanced their angiogenic ability in vitro, which were associated with the up-regulated HIF-1 $\alpha /$ VEGF signaling. Full-thickness cutaneous wound model rats were injected with ASA VI $\left(20 \mathrm{mg}^{\mathrm{k}} \mathrm{kg}^{-1} \cdot \mathrm{d}^{-1}\right.$, iv) for $21 \mathrm{~d}$. Administration of ASA VI significantly promoted the cutaneous wound healing, and more blood vessels were observed in the regenerated tissue. Due to rapid vascularization, the cellular proliferation status, granulation tissue formation, collagen matrix deposition and remodeling processes were all accelerated, resulting in efficient wound healing. In summary, ASA VI promotes angiogenesis of HUVECs in vitro via up-regulating the HIF-1 $\alpha /$ VEGF pathway, and efficiently enhances the vascularization in regenerated tissue and facilitates wound healing in vivo. The results reveal that ASA VI is a potential therapeutic for vessel injury-related wounds.
\end{abstract}

Keywords: asperosaponin VI; traditional Chinese medicine; wound healing; angiogenesis; HIF-1 $\alpha /$ VEGF pathway

Acta Pharmacologica Sinica (2018) 39: 393-404; doi: 10.1038/aps.2017.161; published online 7 Dec 2017

\section{Introduction}

Skin wounds caused by trauma, burns and chronic diseases are a major public health problem around the world, which usually cause pain, infections, and even amputation in millions of patients, and result in decreases in quality of life and a heavy medical burden ${ }^{[1,2]}$. The interrupted or injured skin caused by physical, bacterial, chemical, or viral insults, as well as their structure and function, could be repaired and regenerated through a wound healing process ${ }^{[3,4]}$. In general, wound healing is a complex process that is classically divided into four stages: clot formation, inflammation, proliferation, and remodeling ${ }^{[5-7]}$. Stimulation of new blood vessel formation and proliferation of fibroblasts and keratinocytes play a vital

\footnotetext{
*To whom correspondence should be addressed.

E-mail spinexu@163.com (Hua-zi XU); maocong@wmu.edu.cn (Cong MAO)

Received 2017-05-29 Accepted 2017-08-17
}

role in wound healing. Additionally, production of basement membrane area and connective tissue provide a favorable wound bed for skin regeneration ${ }^{[8,9]}$.

Angiogenesis is critical for wound healing, especially for recovering from chronic and ischemic injuries. Newly formed blood vessels are essential for tissue repair because they can support cells at the wound site with nutrition and oxygen. Early post-injury, angiogenesis cytokines, such as vascular endothelial growth factor (VEGF), could be induced by hypoxia, which is an important stimulus for the wound healing process. VEGF is an essential factor for vascular formation and can increase the survival, proliferation and migration of endothelial cells and further promote angiogenesis ${ }^{[10-13]}$. Hypoxia-inducible factor-1 (HIF-1), which is a heterodimeric transcription factor complex consisting of $\alpha$ and $\beta$ subunits, regulates cytokines and cellular oxygen homeostasis, especially under hypoxic condition ${ }^{[14,15]}$. Several growth factors, including basic fibroblast growth factor (bFGF) and VEGF, 
were used to treat ischemic disease, such as diabetes ${ }^{[16]}$, ischemic hind limb ${ }^{[17]}$ and myocardial infarction ${ }^{[18,19]}$. Interestingly, this approach resulted in faster cell proliferation, migration, differentiation and other angiogenic activities of endothelial cells ${ }^{[20]}$. However, high-dose requirements associated with high expenses, short protein half-life and undesired side effects limit the clinical use of growth factors ${ }^{[21]}$. Consequently, seeking a non-toxic agent that could enhance angiogenesis and accelerate wound healing would be very useful for developing a potential alternative agent $t^{[22]}$.

Numerous studies have showed that multiple herbs and herbal extracts of traditional Chinese medicine (TCM) are effective for the treatment of vascular diseases, such as atherosclerosis ${ }^{[23]}$. Dipsacus asper Wall, which belongs to Dipsacaceae, is a perennial herb growing in moist fields and mountains ${ }^{[22]}$. Dipsacus asper Wall is a widely used TCM herb as a tonic agent in spermatorrhea, and is also used as an analgesic agent for treating pain and an anti-inflammatory agent for treating fractures $^{[24]}$. Several chemical constituents, particularly Dipsacus saponins, have been identified from the root of Dipsacus asper ${ }^{[25]}$. Dipsacus asper Wall extracts exert anti-complementary, antinociceptive and neuroprotective activities ${ }^{[26]}$. Asperosaponin VI (ASA VI), which is a triterpene saponin and pharmacologically active constituent derived from Dipsacus asper Wall, has various bioactive effects, including neuroprotection, osteoporosis prevention, myocardial protection, anti-apoptosis and analgesia ${ }^{[26-28]}$. However, the potential angio-modulatory role of ASA VI is poorly understood. In this study, it is hypothesized that ASA VI may promote angiogenesis and accelerate wound healing.

In this study, the angiogenesis promoting effect of ASA VI in human umbilical vein endothelial cells (HUVECs) and the mechanism underlying the angiogenesis effects of ASA VI on HUVECs were studied. A full-thickness cutaneous wound model was also used to evaluate the therapeutic potential of ASA VI.

\section{Materials and methods Materials and reagents}

Calcium fluorescein-AM and dimethylsulfoxide (DMSO) were provided by Sigma Aldrich (St Louis, MO, USA). Monoclonal antibodies specific for GAPDH and cell nuclear antigen (PCNA) were purchased from Cell Signaling Technologies (Beverly, MA, USA). Monoclonal antibodies specific for a-SMA, Cytokeratin, HIF-1a and VEGF and fluorescein isothiocyanate-labeled and horseradish peroxidase-labeled secondary antibodies were purchased from Abcam (Cambridge, UK). PX-478 was purchased from Selleckchem (Houston, TX, USA). Human basic fibroblast growth factor (bFGF) was purchased from Peprotech (London, UK). Crystal violet and 4',6-diamidino-2-phenylindole (DAPI) were obtained from Beyotime (Shanghai, China). Asperosaponin VI (purity $\geq 98 \%$ ) was purchased from Herbpurify (Chengdu, China).

\section{Cell culture and treatments}

HUVECs were purchased from ATCC (Manassas, VA, USA) and cultured in 1640 medium containing $10 \% \mathrm{FBS}, 100 \mathrm{U} / \mathrm{mL}$ penicillin and $100 \mu \mathrm{g} / \mathrm{mL}$ streptomycin at $37{ }^{\circ} \mathrm{C}$ under $5 \%$ $\mathrm{CO}_{2}$. HUVECs were incubated with different doses of ASA VI $(20,40,80 \mu \mathrm{g} / \mathrm{mL})$ for $48 \mathrm{~h}$ or treated with ASA VI $(80 \mu \mathrm{g} / \mathrm{mL})$ for different periods $(0,12,24,48 \mathrm{~h})$. For tube formation and Western blot analysis, a group of HUVECs were pretreated with PX-478 $(20 \mu \mathrm{mol} / \mathrm{L})$ for $12 \mathrm{~h}$ followed by treatment with ASA VI for $48 \mathrm{~h}$.

\section{Assessment of cellular viability and proliferation}

Cell viability was evaluated by Cell Counting Kit-8 assays (CCK-8; Dojindo Co, Japan) according to the manufacturer's instructions. In brief, HUVECs were seeded on 96-well plates (5000 cells/well) at $37^{\circ} \mathrm{C}$ for $24 \mathrm{~h}$. Cells were treated with different concentrations of ASA VI $(10,20,40,80$ and $160 \mu \mathrm{g} / \mathrm{mL})$ for $48 \mathrm{~h}$. After treatment, $10 \mu \mathrm{L}$ of tetrazolium substrate were added, and the plates were cultured in dark for $1 \mathrm{~h}$. The absorbance was measured at $450 \mathrm{~nm}$ using a microplate reader (Thermo Scientific, Multiskan Go).

Cell proliferation was assessed by an EDU test using a CellLight EdU cell proliferation kit (RiboBio Co, Ltd) combining Hoechst 33342 staining according to the manufacturer's instructions. Briefly, $80 \%$ confluent HUVECs were harvested and plated onto a 96-well plate. After cells adhered to the plate, different doses of ASA VI were added into the cells and cultured for $48 \mathrm{~h}$. The EdU reagent $(0.5 \mu \mathrm{L}, 50 \mu \mathrm{mol} / \mathrm{L})$ was then added into each well containing $500 \mu \mathrm{L}$ of medium and incubated for $4 \mathrm{~h}$. Cells were fixed using $4 \%$ paraformaldehyde and incubated with $2 \mathrm{mg} / \mathrm{mL}$ aminoacetic acid for 5 min under oscillation. Next, cells were incubated with $100 \mu \mathrm{L}$ of the penetrant in each well for 10 min under oscillation followed by treatment with $100 \mu \mathrm{L}$ of $1 \times$ EdU solution for $30 \mathrm{~min}$. Hoechst 33342 was used to stain cell nuclei. The stained cells were observed under a fluorescence microscope (Nikon).

The cell proliferation marker of PCNA was also tested using Western blot analysis. Briefly, cells were treated with different concentrations of ASA VI $(10,20,40,80 \mu \mathrm{g} / \mathrm{mL})$ for $48 \mathrm{~h}$. Other groups of cells were treated by $80 \mu \mathrm{g} / \mathrm{mL}$ ASA VI for 12, 24 and $48 \mathrm{~h}$. The protein levels of PCNA in HUVECs treated with different dose of ASA VI or different times were detected by Western blot analysis.

\section{Cell adhesion assay Cell-matrix adhesion assay}

The cell-matrix adhesion assay was performed as previously described $^{[29]}$. Briefly, HUVECs $\left(1 \times 10^{4}\right.$ cells/well), pretreated with different concentrations of ASA VI $(0,20,40$ and 80 $\mu \mathrm{g} / \mathrm{mL}$ ) or treated with bFGF $(50 \mathrm{ng} / \mathrm{mL})$ as a positive control, were seeded into culture plates pre-coated with human fibronectin $(1 \mu \mathrm{g} / \mathrm{mL}, \mathrm{F} 0895$, Sigma $)$ and incubated at $37^{\circ} \mathrm{C}$ for 30 min followed by washing cells with PBS three times. Adherent cells were later fixed and stained with Hoechst 33258 (Beyotime, Shanghai, China). Five random fields were visualized and counted under a fluorescence microscope (Nikon).

\section{Cell-cell adhesion assay}

The effects of ASA VI on intercellular adhesion was studied 
by a cell-cell adhesion assay ${ }^{[29]}$. Briefly, completely confluent HUVECs were first stained with Hoechst 33258. Another group of HUVECs was pretreated with ASA VI $(0,20,40,80$ $\mu \mathrm{g} / \mathrm{mL})$ or treated with bFGF $(50 \mathrm{ng} / \mathrm{mL}$ ) as a positive control for $48 \mathrm{~h}$, followed by treatment with calcein-AM, a cyto-membrane tracker, for $30 \mathrm{~min}$ at $37^{\circ} \mathrm{C}$ and subsequently seeded onto the Hoechst 33258-labeled cell monolayer (acceptor cells). After $30 \mathrm{~min}$, the attachment and spread of seeded cells that remained attached after three gentle washes with PBS were monitored and recorded with a fluorescence microscope (Nikon).

\section{Cell migration assay}

A Transwell assay $(8 \mu \mathrm{m})$ (Corning, USA) was used to evaluate the migration ability of HUVECs. Briefly, $1 \times 10^{5}$ cells were seeded in the upper chamber, while the lower chamber contained culture medium with $1 \%$ FBS and different concentrations of ASA VI $(0,20,40$ and $80 \mu \mathrm{g} / \mathrm{mL})$. Cells treated with bFGF ( $50 \mathrm{ng} / \mathrm{mL}$ ) were used as a positive control. After $12 \mathrm{~h}$ of incubation, the membrane of the upper chamber was carefully removed by cotton swab, fixed in $4 \%$ paraformaldehyde for 30 $\mathrm{min}$ at room temperature and then stained with crystal violet to quantify the migrated cells. The migrated cells were examined using an inverted microscope (Nikon, ECLIPSE Ti, Japan). All experiments were performed three times and 10 random fields of HUVECs were counted for statistical analysis.

\section{In vitro tube formation assay}

A tube formation assay on Matrigel (BD Biosciences, USA) was performed to evaluate the effects of ASA VI on HUVECs morphogenesis and tube formation capacity. Briefly, Matrigel solution was thawed at $4^{\circ} \mathrm{C}$ overnight and placed in a $\mu$-Slide (10 $\mu \mathrm{L}$ per well, IBIDI, Germany) in a cell incubator for $1 \mathrm{~h}$ to solidify. A total of 5000 cells, which were pre-treated with different concentrations of ASA VI $(0,20,40$ and $80 \mu \mathrm{g} / \mathrm{mL})$ and cells treated with bFGF ( $50 \mathrm{ng} / \mathrm{mL}$ ) as a positive control were seeded in the Matrigel precoated $\mu$-Slide. A group of HUVECs were pretreated with PX-478 $(20 \mu \mathrm{mol} / \mathrm{L})$ for $12 \mathrm{~h}$ followed by treatment with ASA VI $(80 \mu \mathrm{g} / \mathrm{mL})$ for $48 \mathrm{~h}$. Tube formation was observed and quantified, and five independent fields were counted to obtain an average number under an inverted light microscope (Nikon).

\section{Establishment of a wound model}

All animals were ordered from the SLAC Laboratory Animal Company in Shanghai, China, and all animal procedures were approved by the Wenzhou Medical University Animal Care and Use Committee (approval license number: wydw20160157). Twenty SD rats were anesthetized with $2.5 \%$ pentobarbital sodium $(30 \mathrm{mg} / \mathrm{kg}$ ). After shaving and sterilization, two full-thickness wounds ( $20 \mathrm{~mm}$ in diameter) were made on each side of the rat's back. After surgery, the ASA VI was immediately injected intravenously to deliver a dose of $20 \mathrm{mg} \cdot \mathrm{kg}^{-1} \cdot \mathrm{d}^{-1}$ until the rats were sacrificed ${ }^{[30]}$. Equivalent normal saline injections were administered for vehicle control. All rats were housed in individual cages, and images of the wounds were taken every $7 \mathrm{~d}$. The wound area was calculated by tracing the wound margins and was evaluated as a percent area of the original wound using Image-Pro Plus 6.0 software.

\section{Histology and immunofluorescence}

The rats ( $n=10$ per group) were sacrificed with $10 \%$ chloral hydrate $(3.5 \mathrm{~mL} / \mathrm{kg}, \mathrm{ip})$ at specific time points post-operation. For the H\&E staining, Masson staining and immunofluorescence analyses, $0.5-\mathrm{cm}$ sections of the skin were dissected out, fixed with $4 \%$ paraformaldehyde for $6 \mathrm{~h}$ and then embedded in paraffin. Longitudinal sections (5 $\mu \mathrm{m}$ thick) were mounted on slides. Histopathological examinations were performed by H\&E and Masson staining according to the manufacturers' instructions. Images were acquired using a light microscopy (Olympus, Tokyo, Japan). For immunofluorescence analysis, the longitudinal sections were treated with the following primary antibodies: mouse monoclonal anti-PCNA (1:200), rabbit polyclonal anti-cytokeratin (1:200) and rabbit polyclonal antia-SMA (1:200) before the sections were washed four times with PBS and incubated with AlexaFluor 568 and AlexaFluor 488 donkey anti-rabbit/mouse secondary antibodies for $1 \mathrm{~h}$ at $37^{\circ} \mathrm{C}$. Then, the sections were washed with PBS, incubated with DAPI for $1 \mathrm{~min}$, rinsed with PBS and finally sealed with a coverslip. All images were captured on a fluorescence microscope (Nikon, Japan).

\section{Western blot analysis}

The cell supernatants and tissue specimens were collected for protein assay. The extracts were first quantified with BCA reagents. Then, the cellular samples containing $30 \mu \mathrm{g}$ of protein and tissue samples containing $80 \mu \mathrm{g}$ of protein were separated on SDS-PAGE before being transferred to PVDF membranes and incubated with the appropriate primary antibodies, including anti-PCNA (1:1000), anti-HIF-1a (1:1000), anti-VEGF (1:1000) and anti-GAPDH (1:1000) overnight. The samples were then incubated with horseradish peroxidaseconjugated secondary antibodies for $2 \mathrm{~h}$. The bands were detected by electrochemiluminescence reagent (Invitrogen), and the signals were visualized by a Chemi DocXRS ${ }^{+}$Imaging System (Bio-Rad).

\section{Statistical analysis}

Numerical data from at least three individual experiments are shown as the mean $\pm S D$ unless otherwise indicated. The data were analyzed by one-way analysis of variance (ANOVA, Tukey's post-hoc analysis) using GraphPad Prism 7.0 (La Jolla, CA, USA). Statistical significance was set at $P<0.05, P<0.01$ versus the indicated group.

\section{Results}

\section{ASA VI promoted the proliferation of HUVECs}

Cell numbers were significantly increased after incubation with 40 and $80 \mu \mathrm{g} / \mathrm{mL}$ of ASA VI and peaked at $80 \mu \mathrm{g} / \mathrm{mL}$ of ASA VI treatment for $48 \mathrm{~h}$ (Figure 1A). EdU test results indicated that the proliferation of HUVECs can be enhanced with the increase of ASA VI dose (Figure 1B and 1C), which showed 
A

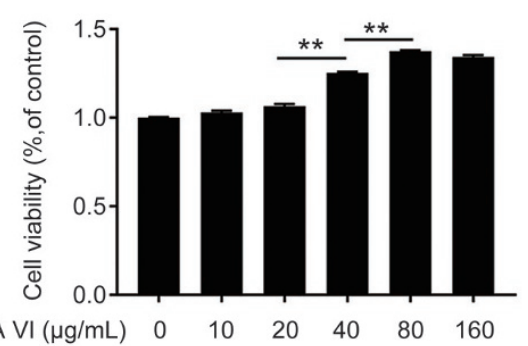

C

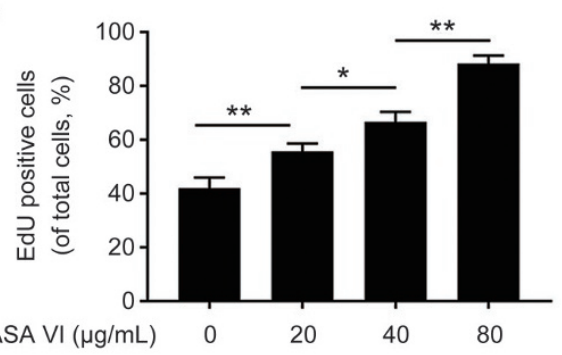

D

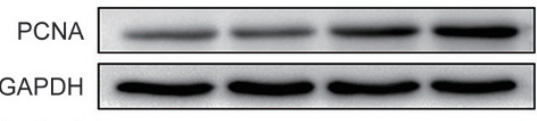

ASA VI $(\mu \mathrm{g} / \mathrm{mL}) \quad 0 \quad 20 \quad 40 \quad 80$

E

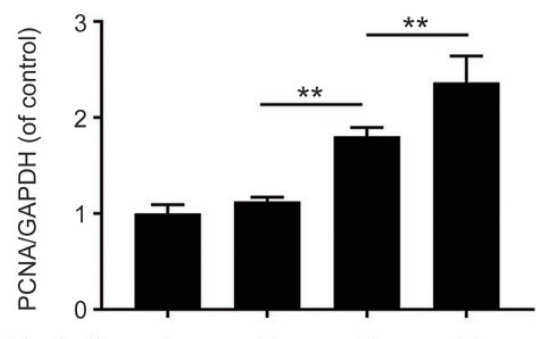

ASA VI $(\mu \mathrm{g} / \mathrm{mL}) \quad 0 \quad 20 \quad 40 \quad 80$
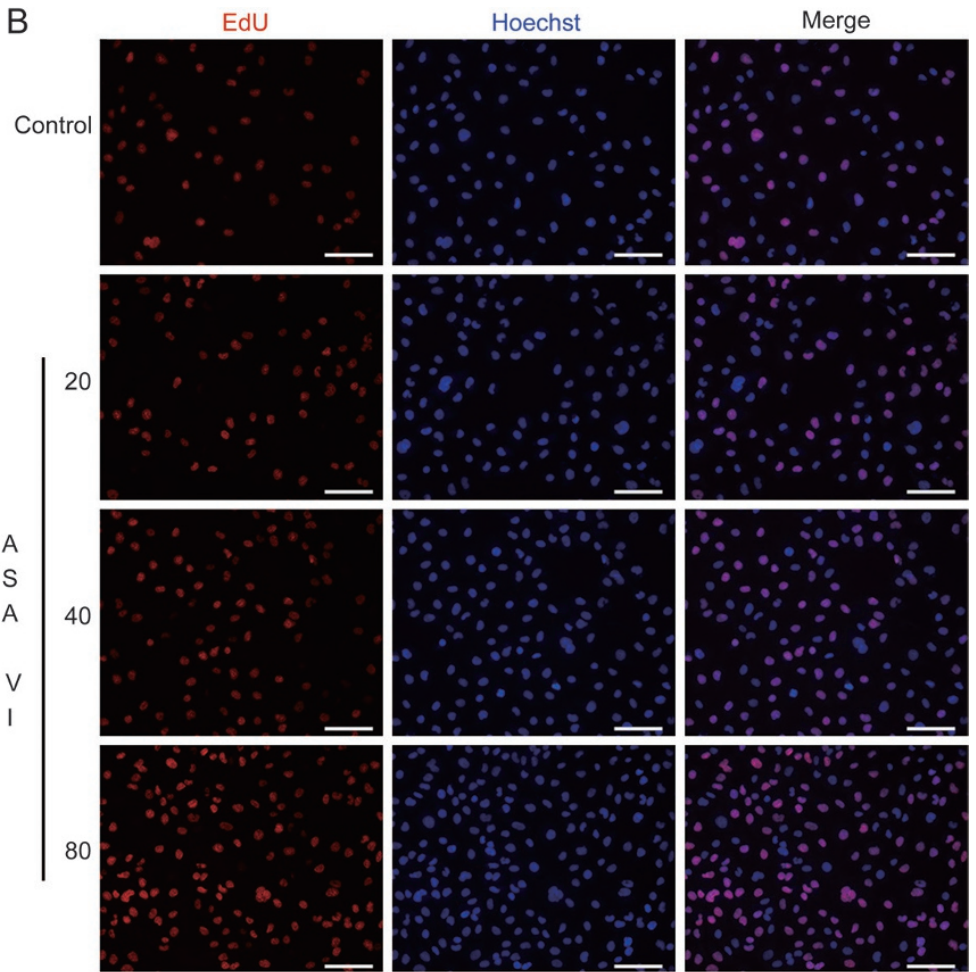

F

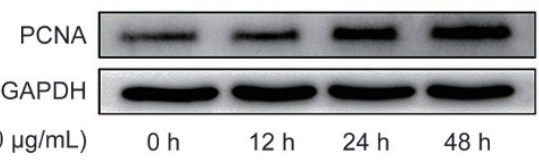

G

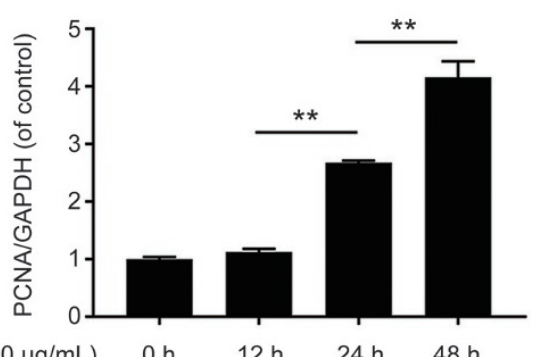

ASA VI $(80 \mu \mathrm{g} / \mathrm{mL}) \quad 0 \mathrm{~h} \quad 12 \mathrm{~h} \quad 24 \mathrm{~h} \quad 48 \mathrm{~h}$

Figure 1. ASA VI promoted proliferation of HUVECs. (A) Cell viability results of HUVECs treated with different concentrations of ASA VI for $48 \mathrm{~h}$. The cells proliferated faster after ASA VI treatment. (B) EdU cell proliferation test results of HUVECs treated with different concentrations of ASA VI (scale bar: $100 \mu \mathrm{m})$. (C) The relative number of HUVECs stained by EdU in each group; (D, E, F, G) PCNA expression in ASA VI-treated cells. ASA VI increased PCNA expression in a dose- and time-dependent manner. The densitometric analysis of all Western blot bands was normalized to the total proteins or GAPDH. $n=3$ independent experiments. ${ }^{*} P<0.05,{ }^{* *} P<0.01$.

a similar pattern to the CCK-8 results. The protein level of PCNA was also enhanced by ASA VI $(20,40$ and $80 \mu \mathrm{g} / \mathrm{mL})$ in a dose-dependent manner (Figure 1D and 1E). Furthermore, the level of PCNA in cells treated with a high dose $(80 \mu \mathrm{g} / \mathrm{mL})$ of ASA VI was up-regulated over time (Figure $1 \mathrm{~F}$ and $1 \mathrm{G}$ ).

\section{ASA VI enhanced cell-matrix adhesion and reduced cell-cell} adhesion

In this study, human fibronectin was used as an ECM substitute to study the effect of ASA VI on cell-matrix adhesion. The results showed ASA VI-treated cells attached to the ECM gel more easily than control cells (Figure 2A). For cell-cell adhesion, ASA VI treatment significantly reduced the adhesive ability of cells to the HUVECs monolayer at $20 \mu \mathrm{g} / \mathrm{mL}$ and bottomed out at $80 \mu \mathrm{g} / \mathrm{mL}$ (Figure 2B). Therefore, ASA $\mathrm{VI}$ augmented cell adhesion to the ECM but reduced cell-cell adhesion capacity.

ASA VI promoted migration and tube formation of HUVECs via the HIF-1 $\alpha /$ VEGF pathway

The directed migration of endothelial cells plays an important role in the beginning of angiogenesis. In this study, a Tran- 
A

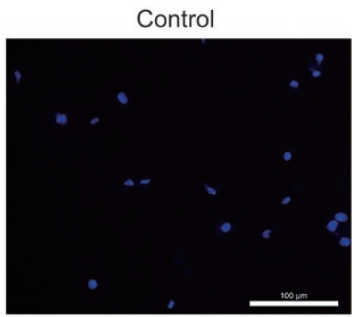

20

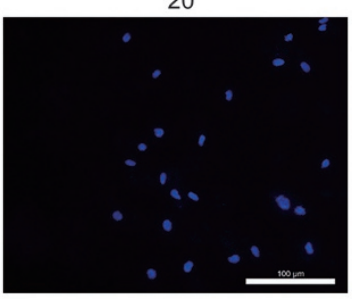

B
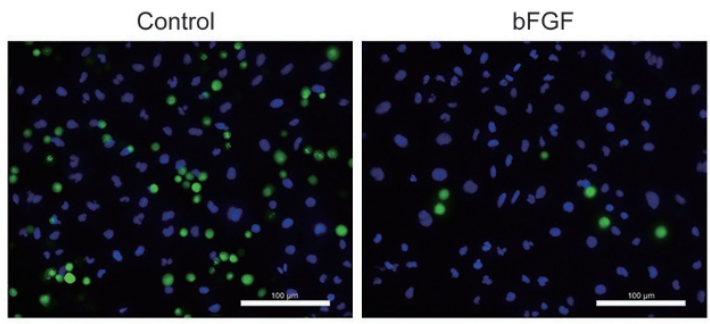

ASA VI $(\mu \mathrm{g} / \mathrm{mL})$

20

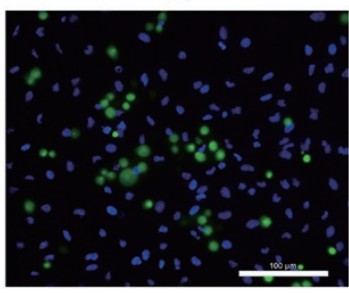

40

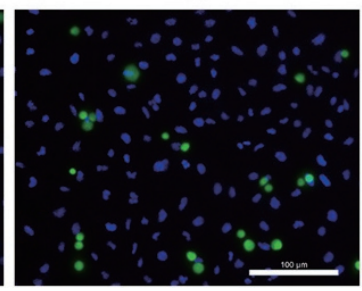

bFGF

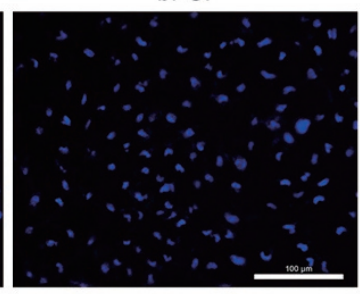

ASA VI $(\mu \mathrm{g} / \mathrm{mL})$
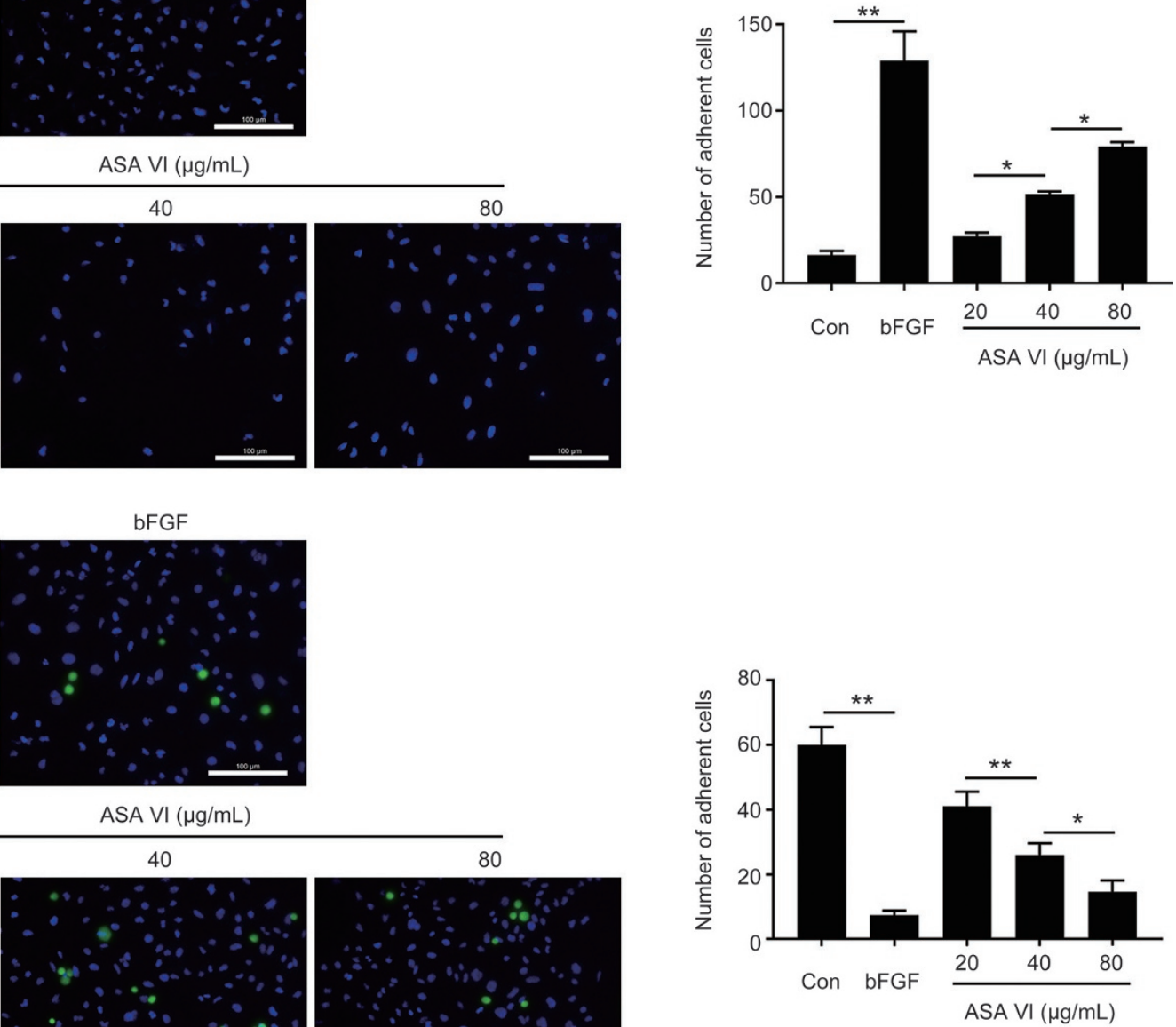

Figure 2. ASA VI increased cell-matrix adhesion and attenuated cell-cell adhesion. (A, B) Cell-matrix adhesion assay results of HUVECs treated with ASA VI. Cell-cell adhesion assay using Hoechst 33258 dye and calcein-AM staining exhibited that ASA VI markedly increased cell-matrix adhesion and decreased cell-cell adhesion (scale bar: $100 \mu \mathrm{m}$ ). $n=3$ independent experiments. ${ }^{*} P<0.05,{ }^{* *} P<0.01$.

swell assay was performed to investigate the ASA VI-driven motility of HUVECs. Interestingly, HUVECs treated with different doses of ASA VI exhibited a remarkably increased migration ability in a dose-dependent manner (Figure 3A), which showed significantly accelerated cell migration with the increase of ASA VI concentration $(20-80 \mu \mathrm{g} / \mathrm{mL})$. Moreover, an in vitro angiogenesis assay was used to investigate the capillary tube formation of HUVECs. Compared to untreated HUVECs, the presence of ASA VI (Figure 3B) significantly increased the number of sprouting tubules in HUVECs, which indicated that ASA VI strongly enhanced the ability of HUVECs to form tube-like structures. Furthermore, Western blot analysis results showed that HIF-1a and VEGF expression were evidently increased after ASA VI treatment in a dose-dependent manner (Figure 4A), and co-treatment with PX-478 (an inhibitor of HIF-1a) and ASA VI could remarkably decrease the HIF-1a and VEGF expression (Figure 4B) compared to ASA VI treatment alone. Additionally, the in vitro tube formation ability of HUVECs stimulated by ASA VI was also impaired by the HIF-1a inhibitor (Figure 4C). Taken together, the HIF-1a/VEGF signaling pathway could play a vital role in up-regulating the angiogenic ability of ASA VI in HUVECs.

\section{ASA VI accelerated cutaneous wound healing in rats}

Based on the above results, ASA VI possesses angiogenic effects in vitro, which may facilitate cutaneous wound healing in vivo. Therefore, the wound healing ability of ASA VI was investigated in a full-thickness cutaneous wound model. Wounds treated with ASA VI $\left(20 \mathrm{mg} \cdot \mathrm{kg}^{-1} \cdot \mathrm{d}^{-1}\right)$ reduced more quickly than wounds in control groups (Figure 5A and 5B). Wound areas began to shrink rapidly during the first week. By d 7, ASA VI-treated wounds achieved nearly $62 \%$ closure compared to the $72 \%$ wound closure observed in controls. On 
A

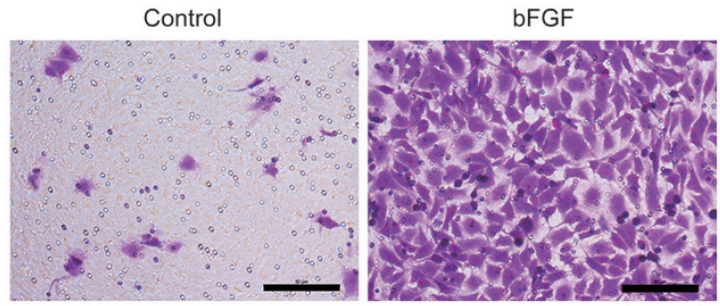

ASA VI $(\mu \mathrm{g} / \mathrm{mL})$
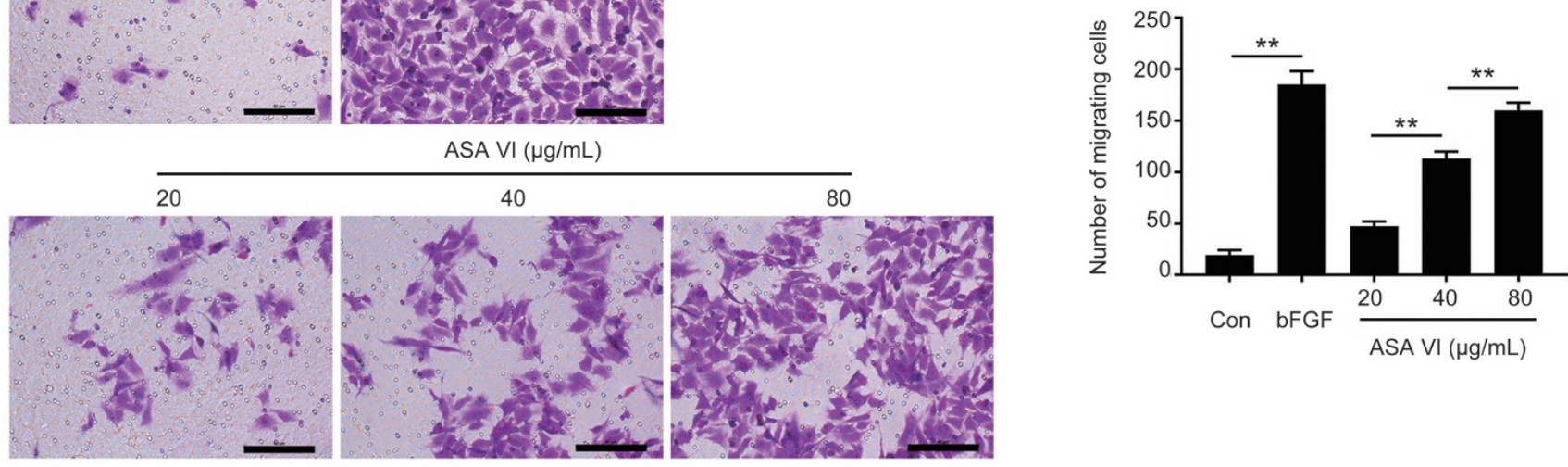

B
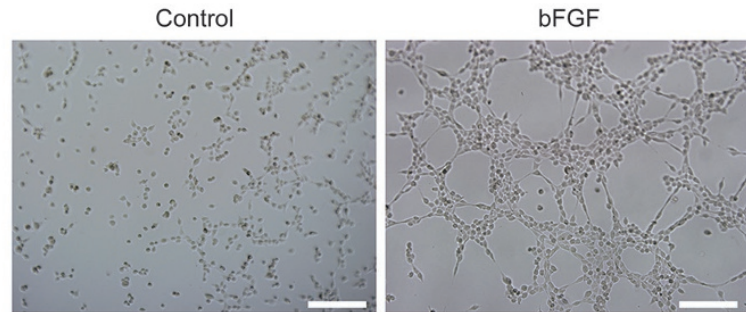

ASA VI $(\mu \mathrm{g} / \mathrm{mL})$
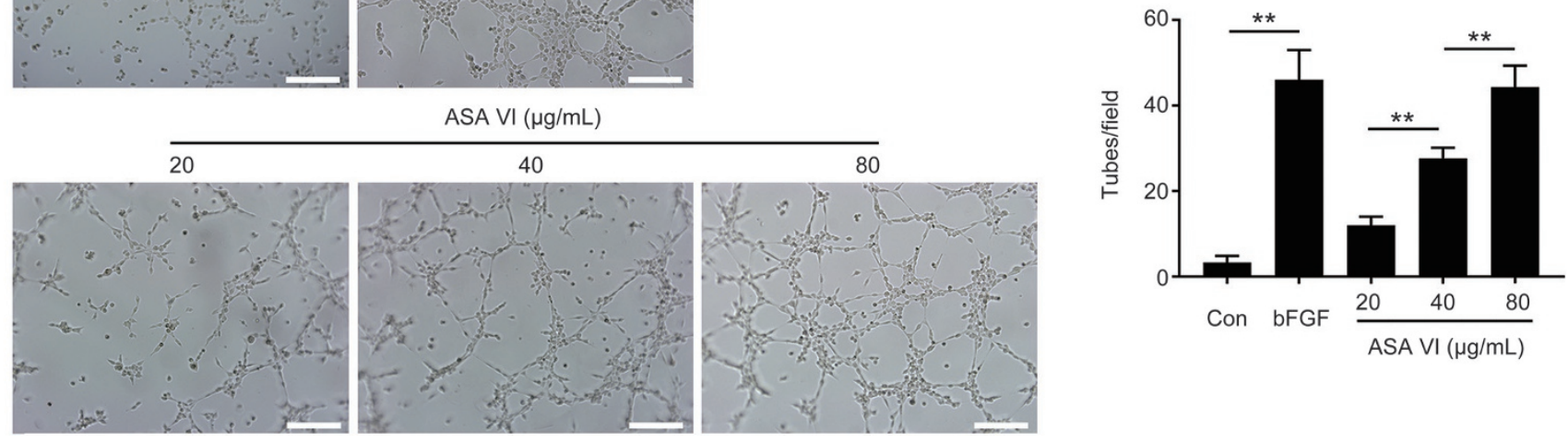

Figure 3. ASA VI enhanced migration and tube formation of HUVECs. (A) Transwell migration assay results of HUVECs with different treatments. HUVECs were treated with PBS (control), $50 \mathrm{ng} / \mathrm{mL}$ bFGF and 20,40, and $80 \mu \mathrm{g} / \mathrm{mL} \mathrm{ASA} \mathrm{VI} \mathrm{in} \mathrm{the} \mathrm{lower} \mathrm{chamber} \mathrm{for} 3 \mathrm{~h}$ incubation. The migration of HUVECs was enhanced after ASA VI treatment (scale bar: $50 \mu \mathrm{m}$ ). (B) In vitro tube formation results of HUVECs treated by ASA VI. The tube formation ability of HUVECs was improved after ASA VI treatment (scale bar: $200 \mu \mathrm{m}$ ). $n=3$ independent experiments. ${ }^{*} P<0.05,{ }^{* *} P<0.01$.

d 14, the healing rate of the ASA VI group slowed, but healing still occurred at a significantly higher rate than control groups. By d 21, wounds in the ASA VI group were completely closed, whereas some of the control wounds remained unhealed (Figure $5 \mathrm{C}$ ). These results demonstrated that ASA VI accelerates wound healing in vivo.

\section{ASA VI improved granulation and capillary formation in vivo}

The H\&E staining results of wound sections treated with ASA VI (Figure 6A) at d 7 revealed no obvious neo-epidermis beneath the eschar in the ASA VI treatment group compared to the control, while the length of the wound margin and the thickness of granulation were significantly different between the two groups (Figure 6B and 6C). At d 14, neo-epidermis formation was observed in two groups, and the granulation of ASA VI treatment groups was still thicker than the control groups. The results showed that the lengths of wounds in the
ASA VI treatment groups were shorter (Figure 6B), but there were thicker and continuous layers of granulation across the entire wound gap compared to the control (Figure 6C), which indicated that ASA VI can improve the granulation formation speed. Furthermore, the number of capillaries on the wound bed or wound edge was significantly higher in ASA VI groups compared to the control (Figure 6D and 6E), suggesting that ASA VI treatment can remarkably enhance the capillary formation both in the wound bed and edge in vivo.

\section{ASA VI accelerated collagen deposition and remodeling}

The Masson Trichrome staining results of wound sections at d 7 revealed strong blue staining in ASA VI-treated groups (Figure 7), which suggests there was abundant regenerated collagen deposition. Additionally, compared to the control, ASA VI-treated wounds had densely packed collagen fibers running in a parallel arrangement, whereas irregularly orga- 
A

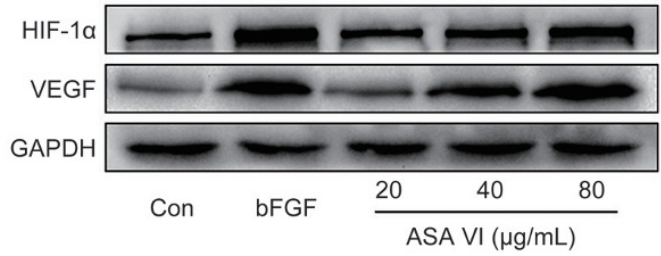

B

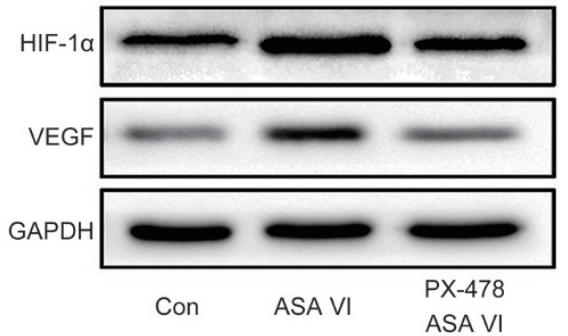

C

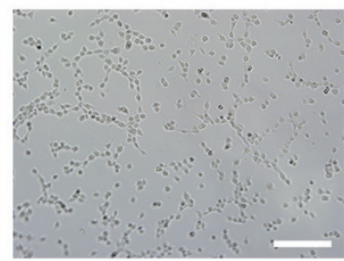

Control

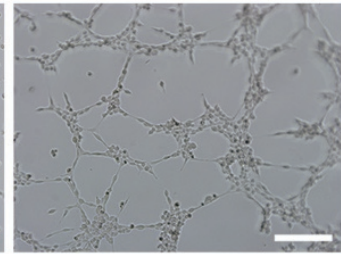

ASA VI
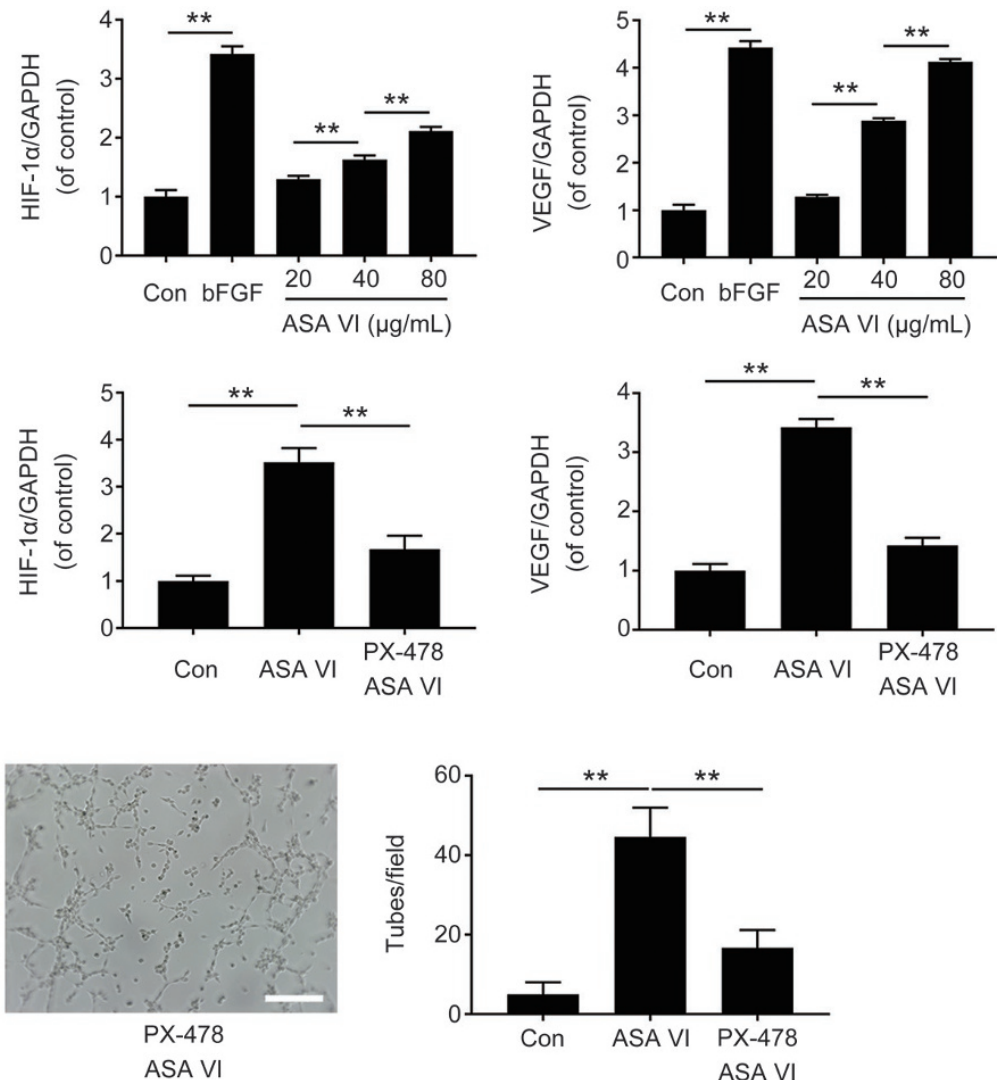

Figure 4. ASA VI exerts angiogenic ability via the HIF-1 $\alpha$ /VEGF pathway. (A) Western blot analysis of protein expression of HIF-1 $\alpha$ and VEGF in HUVECs treated with ASA VI for $48 \mathrm{~h}$. Treatment with ASA VI evidently increased the expression of HIF-1 $\alpha$ and VEGF. (B) Western blot analysis of protein expression of HIF- $1 \alpha$ and VEGF in HUVECs pretreated with PX-478 for $12 \mathrm{~h}$, followed by treatment with ASA VI for $48 \mathrm{~h}$. Pretreatment with PX-478 significantly decreased the expression of HIF- $1 \alpha$ and VEGF. (C) In vitro tube formation results of HUVECs pretreated by PX-478 (scale bar: $200 \mu \mathrm{m}$ ). The densitometric analysis of all Western blot bands was normalized to the total proteins or GAPDH. $n=3$ independent experiments. ${ }^{*} P<0.05,{ }^{* *} P<0.01$.

nized and loosely packed collagen fibers appeared in the control wounds. Consistent with these findings, ASA VI promoted collagen regeneration and remodeling in full-thickness wounds.

\section{ASA VI stimulated cell proliferative activities and cytokeratin expression}

The level of PCNA, which is a biomarker of cell proliferation, was detected using immunofluorescence. The ASA VI-treated wounds had enhanced PCNA positive staining compared to controls on $\mathrm{d} 7$, indicating higher cellular proliferation in the wound area (Figure 8A and 8B). Furthermore, re-epithelialization status was evaluated by detecting the level of related cytokeratin. ASA VI treatment groups exhibited a thicker neo-epidermis than control groups (Figure 8C and 8D) on $\mathrm{d}$ 7 , which was demonstrated by the strong expression of cytokeratin in the thicker epidermis and confirmed the faster reepithelization rate of ASA VI on wounds in vivo.

\section{ASA VI boosted angiogenesis through the HIF-1 $\alpha /$ VEGF pathway} in vivo

As wound healing requires neovascularization, the angiogenesis status of the wounds was studied through immunostain- ing of a-SMA (Figure 9A). Strong positive staining of a-SMA and DAPI on the wound bed confirmed ASA VI treatment significantly enhanced the number of newly formed vessels, suggesting that ASA VI boost angiogenesis and further lead to fast wound healing. Quantitatively, the vessel density of the ASA VI treatment groups was higher compared to the control (Figure 9B). Additionally, Western blotting results showed that HIF-1a/VEGF levels were up-regulated in ASA VI treatment groups compared to the control (Figure 9C-9E). Taken together, ASA VI boosts angiogenesis in full-thickness wounds through the HIF-1a/VEGF pathway.

\section{Discussion}

Wound healing is a biological process that involves interactions between cells, skin ECM and growth factors, and it usually occurs in four processes including clot formation, inflammation, new tissue formation, and remodeling ${ }^{[31]}$. There is an intricate cascade of events in skin repair, but angiogenesis is considered a pivotal process during wound healing ${ }^{[32]}$. According to recent studies, the external application of growth factors could promote angiogenesis at the site of injury and accelerate wound closure ${ }^{[33]}$. However, high costs, short protein half-life and undesirable side effects limit growth factors' 
A

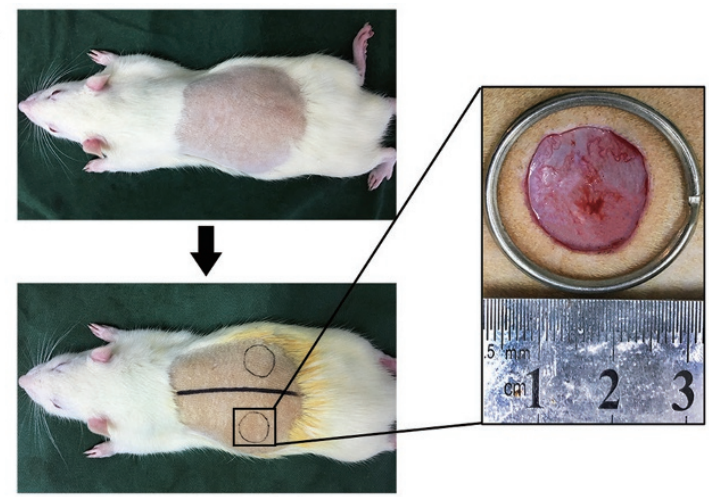

C

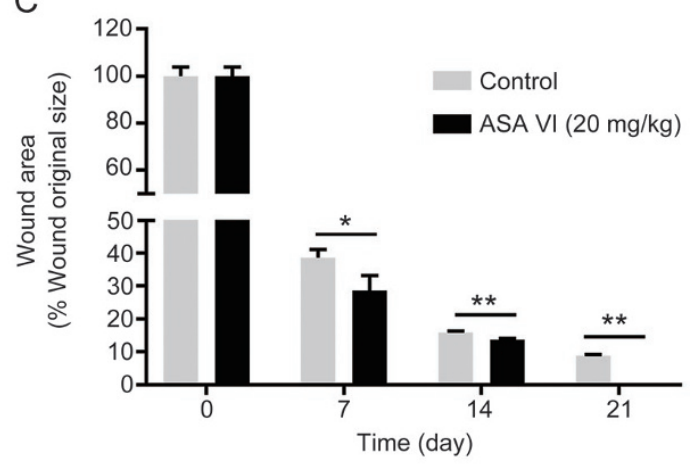

B
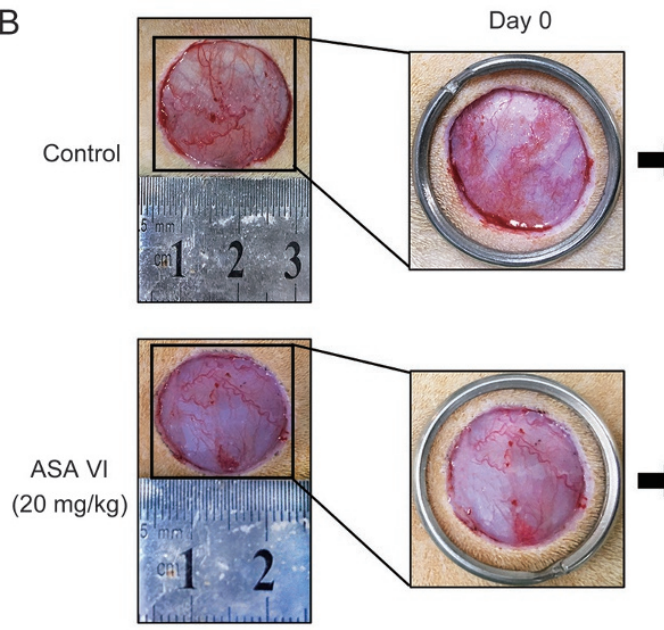
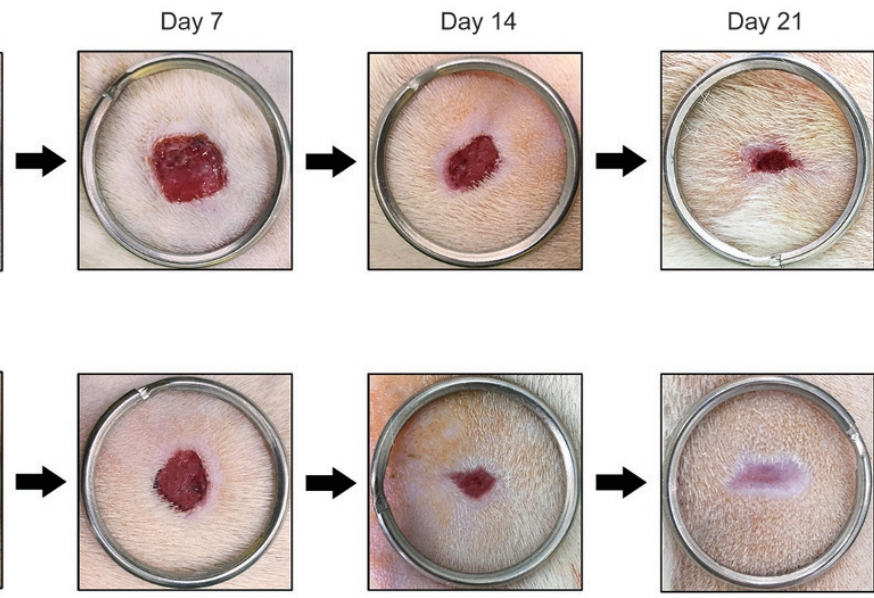

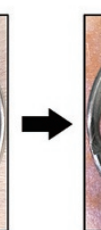

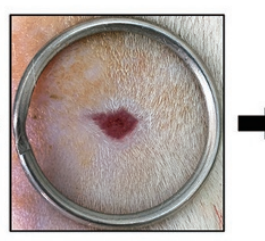

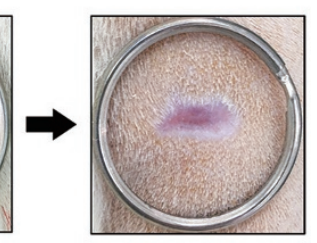

Figure 5. ASA VI accelerated wound healing in rats. (A) The wound healing model used in this study. (B) Representative images of the healing process in ASA VI-treated rats on different days. (C) Wound healing rates at different times. Healing rates of full-thickness cutaneous wounds were significantly increased by the ASA VI treatment. $n=3$ independent experiments. ${ }^{*} P<0.05,{ }^{* *} P<0.01$.

clinical use ${ }^{[21]}$. Thus, the development of therapeutic strategies, including effective and pleiotropic proangiogenic drugs, is urgently needed. In this study, a traditional Chinese medicine named ASA VI, which has multiple therapeutic effects, was employed, and its angiogenic and wound healing abilities were investigated.

Angiogenesis is a complex process requiring multiple sequential steps, including the interplay between cells, soluble factors and ECM components. In this study, a significant proangiogenic effect of ASA VI on HUVECs was observed through faster cell proliferation, as well as regulated adhesion, migration, and in vitro tube formation. Generally, vascular endothelial proliferation is the beginning of angiogenesis followed by separation from adjacent cells, migration, adherence to the ECM and differentiation ${ }^{[34,35]}$. Under the conditions used in this study, ASA VI significantly promoted proliferation of HUVECs at doses over $20 \mu \mathrm{g} / \mathrm{mL}$, which should be an initial sign of angiogenesis. Furthermore, not only is the large number of endothelial cells enhancing revascularization at the wound site, but motility and differentiation are also critical processes in the reconstruction of blood vessel networks. In this study, enhanced cell migration was found in ASA VIstimulated HUVECs, which ultimately benefits the angiogen- esis process. Furthermore, the pretreatment of HUVECs with ASA VI decreased cell-cell adhesion and increased the cellmatrix adhesion, which also supported migration. Furthermore, the ability of endothelial cells to separate from adjacent cells and adhere into ECM would help cells differentiate into new blood vessels, which was confirmed by the faster tube formation rate and tube numbers (Figure 3B), which ultimately indicated the pro-angiogenesis effects of ASA VI.

Emerging reports have suggested that HIF-1a is an important transcription factor that regulates the VEGF gene that is necessary for the wound healing process, and the entire process of normal wound healing is dependent on its expres$\operatorname{sion}^{[36]}$. VEGF is one of the most potent angiogenic cytokines and can promote proliferation of vascular cells. Up-regulating the HIF-1a/VEGF pathway could accelerate wound healing in diabetic rats ${ }^{[37]}$. Our results have shown that ASA VI increased HIF-1a and VEGF expression in HUVECs, and the HIF-1a inhibitor could attenuate the ASA VI-induced angiogenesis, which suggested the pro-angiogenesis effects of ASA VI in HUVECs may primarily act through the HIF-1a/VEGF pathway.

Meanwhile, the effects of ASA VI on full-thickness cutaneous wound healing were investigated in this study. The 
A

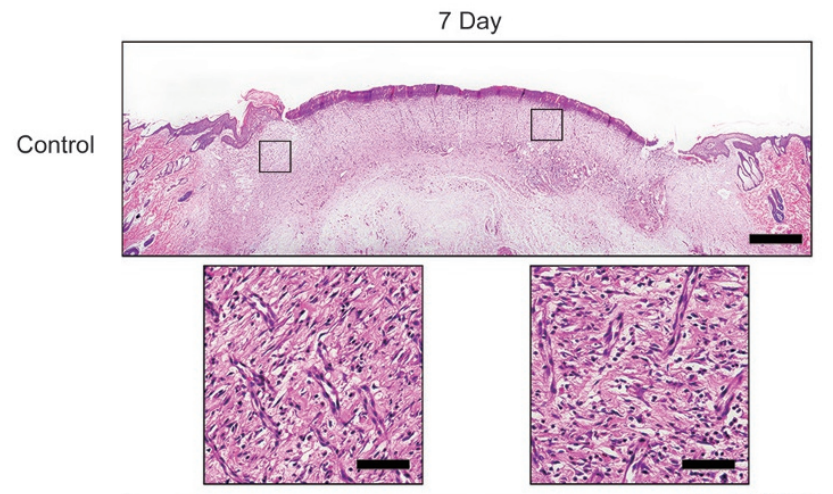

ASA VI (20 mg/kg)

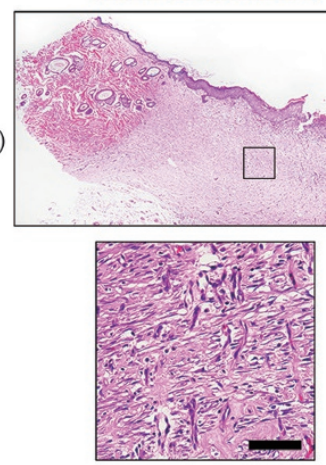

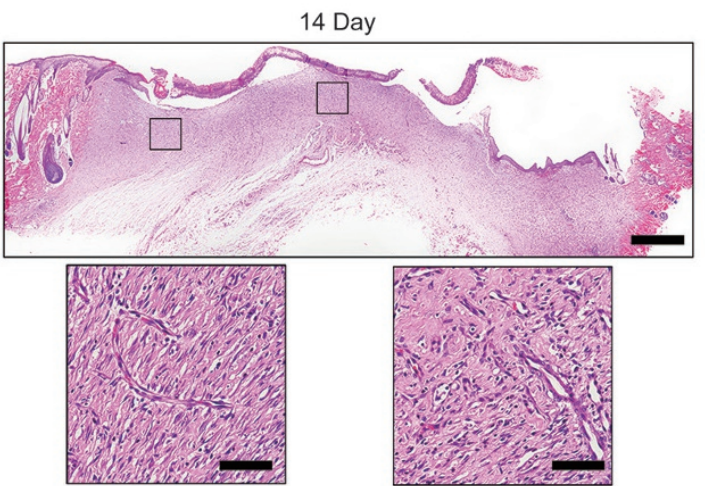
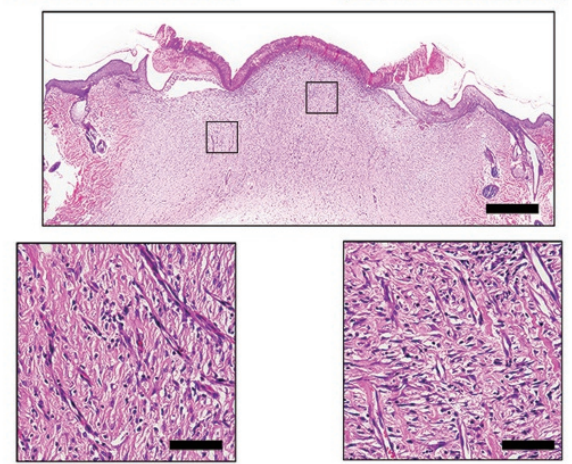

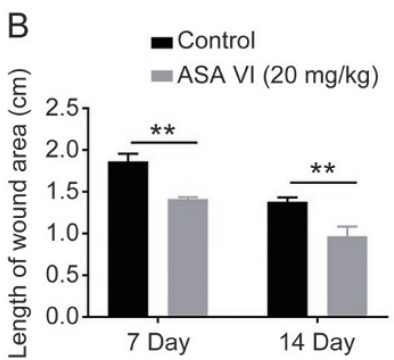

C

- Control - ASA VI $(20 \mathrm{mg} / \mathrm{kg})$

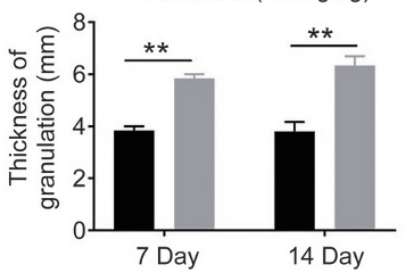

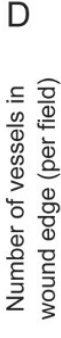

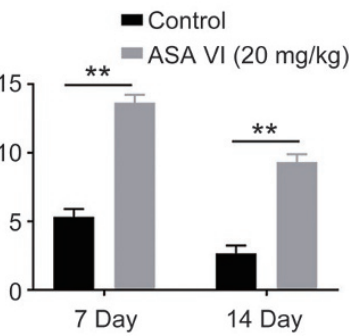

E

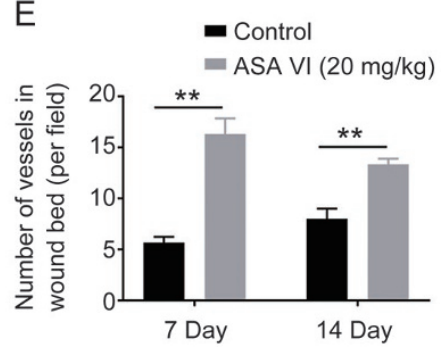

Figure 6. ASA VI increased granulation thickness and capillary formation. (A) Representative images of H\&E staining sections of wounds at 7 and $14 \mathrm{~d}$ post-operation (scale bar: $100 \mu \mathrm{m}, 10 \mu \mathrm{m}$ ). (B, C) Quantification of the length of the wound area and the thickness of the granulation. (D, E) Quantification of the number of vessels in wound edge and wound bed. $n=3$ independent experiments. ${ }^{*} P<0.05,{ }^{* *} P<0.01$.

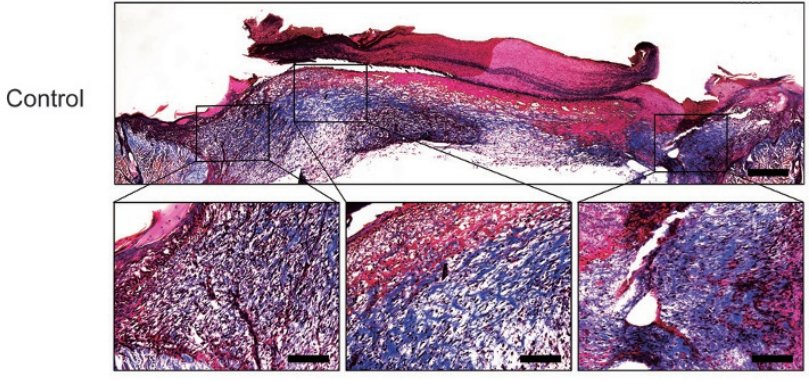

ASA VI $(20 \mathrm{mg} / \mathrm{kg})$

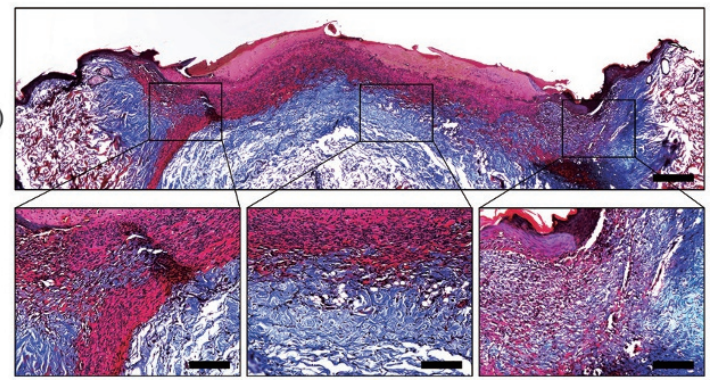

Figure 7. ASA VI enhanced collagen deposition and remodeling. Tissue sections are stained with Masson's trichrome (blue=collagen; red=cytoplasm and muscle fibers). The ASA VI group showed wellorganized and abundant collagen, whereas scattered and disorganized collagen appeared in the control group. The rectangles refer to the closeup areas. Original scale bar $=100 \mu \mathrm{m}$ and close-up scale bar $=10 \mu \mathrm{m}$. 
A
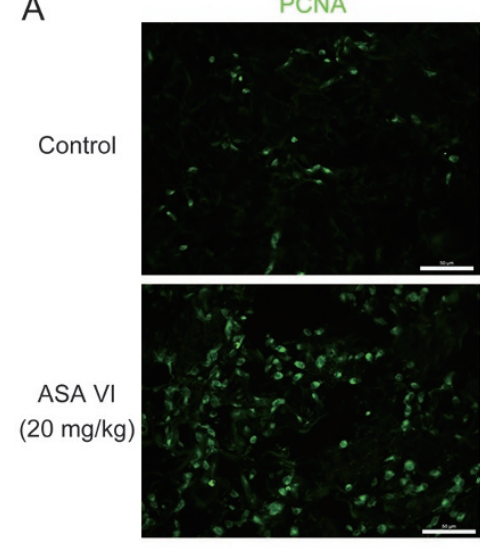

C
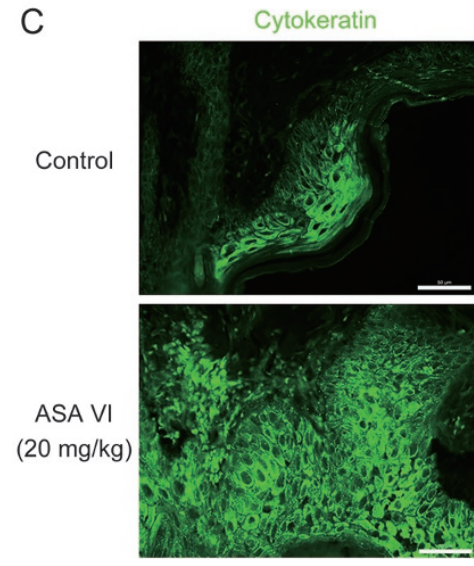
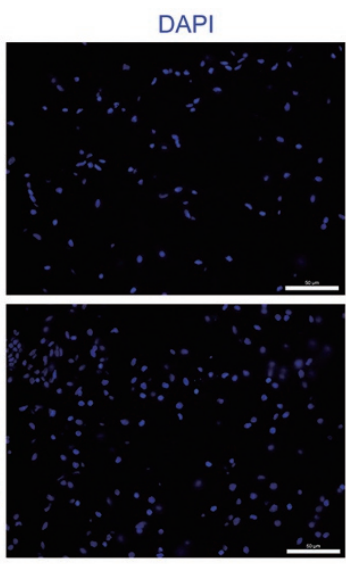

DAPI

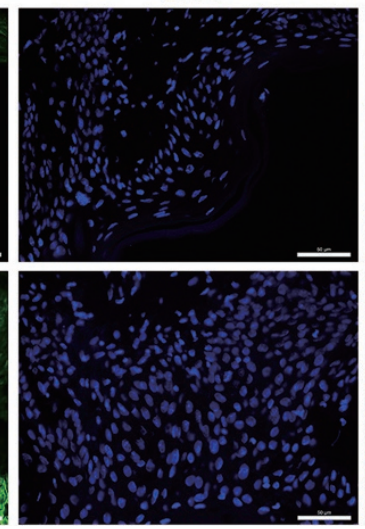

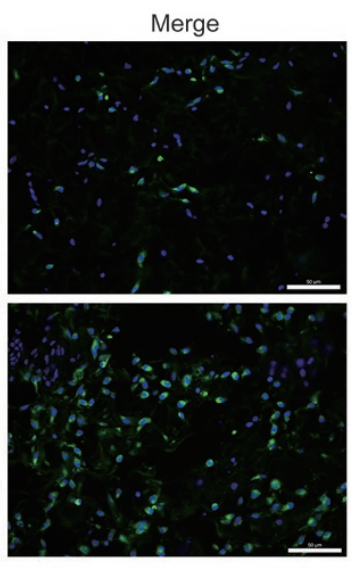

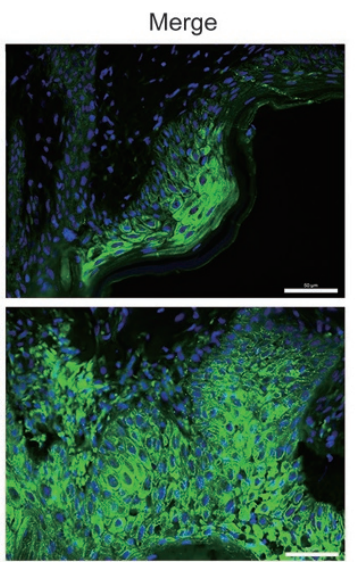

B

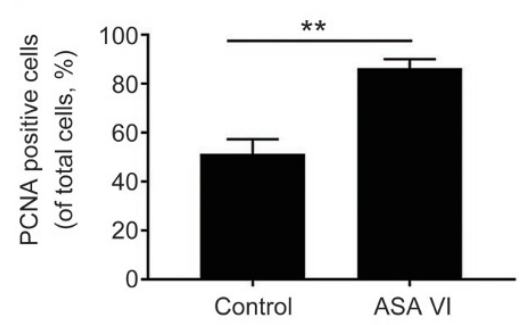

D

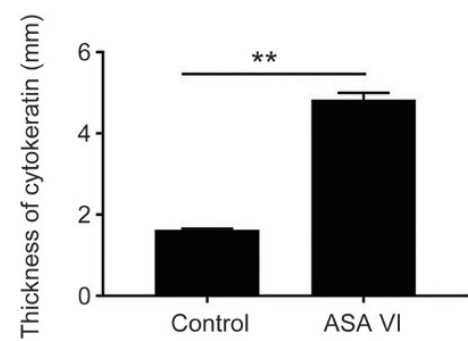

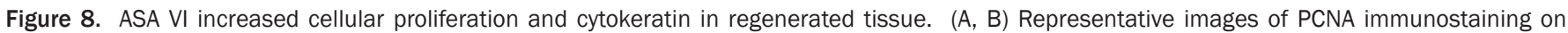

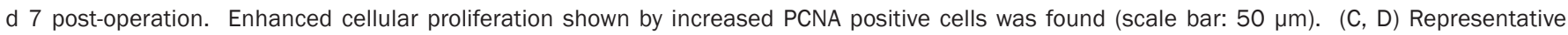

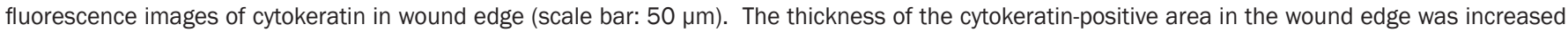
by ASA VI treatment. $n=3$ independent experiments. ${ }^{* *} P<0.01$.

results showed that ASA VI activated cytokeratin expression and improved re-epithelialization of wound regeneration (Figure 8A and 8C). Previous studies showed that cell migration and proliferation, neovascularization, ECM deposition and remodeling are common indicators that reflect the speed of wound healing. After injury, a mass of cells, such as fibroblasts, macrophage and endothelial cells, proliferated and migrated into the wound area to facilitate wound healing. As expected, the level of PCNA, which is a marker of cellular proliferative activity, was significantly enhanced by the ASA VI treatment, suggesting that the faster proliferation rate was stimulated and would facilitate healing. In the early stage, granulation tissue, which usually forms at $2-5 \mathrm{~d}$ in the wound site after injury, can fill the defects, exert anti-infection function and contain abundant cells and cytokines that will benefit wound healing. In our present study, the thickness of granulation tissue in ASA VI treatment groups was significantly thicker than control groups, which indicated that ASA VI could strengthen the granulation tissue formation and further assist wound healing. Furthermore, collagen deposition and remodeling, as promoted by the ASA VI treatment in this study, is a critical factor for determining the strength and appearance of the scar that will be formed after healing $^{[38-40]}$. The well-organized abundant collagen in the wounds treated by the ASA VI could be a regulated result of the higher PCNA level and thicker granulation tissue because collagen fibers were mainly secreted by fibroblasts and can be remodeled by the growth factors contained in the granulation tissue. Another interesting finding was that ASA VI enhanced the newly formed vessels in the wound bed, which supports nutrition and acts as a scaffold for cells to migrate to the wound area and plays a vital role in the wound healing process. Upregulated HIF-1a and VEGF expression were also found in vivo, which suggested that ASA VI-accelerated wound healing may occur via the HIF-1a/VEGF pathway, which may be related to collagen deposition ${ }^{[41,42]}$. Taken together, the faster cell proliferation, granulation tissue formation, collagen deposition and remodeling rates, which may all rely on faster angiogenic ability, would lead to faster and better healing in wounds stimulated by the ASA VI.

In summary, our study provides potent evidence for ASA VI-mediated HIF-1a/VEGF signaling in HUVECs, which leads to increased cell proliferation, migration and angiogenic differentiation. Moreover, due to the fast vascularization in 
A
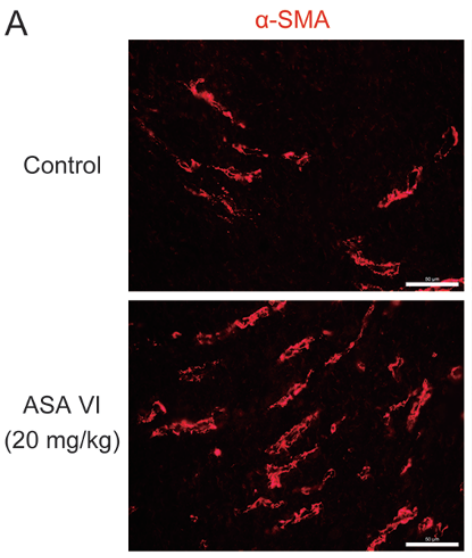

C

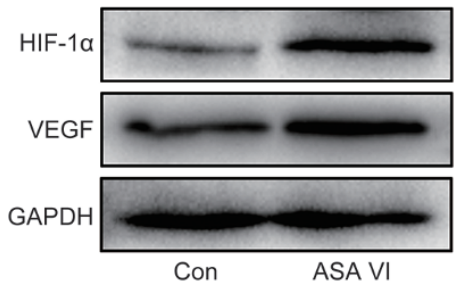

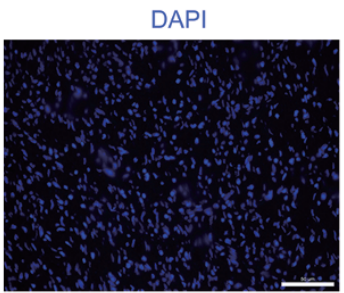

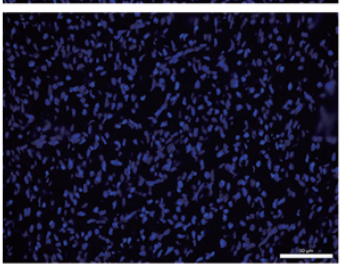

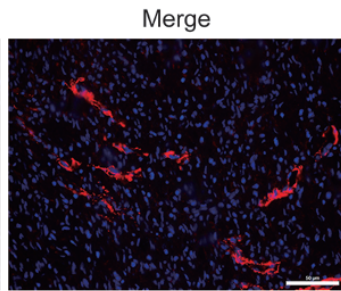
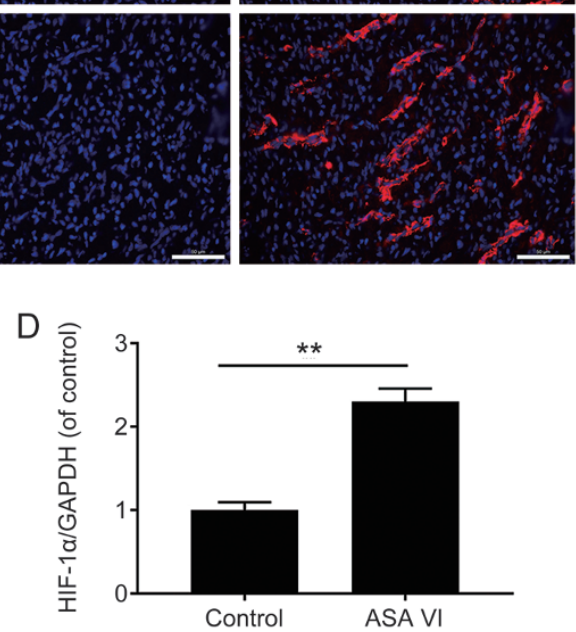

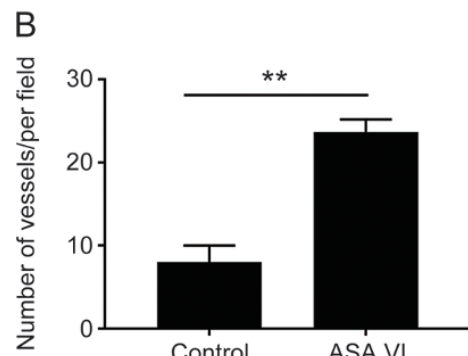

$\mathrm{E}$

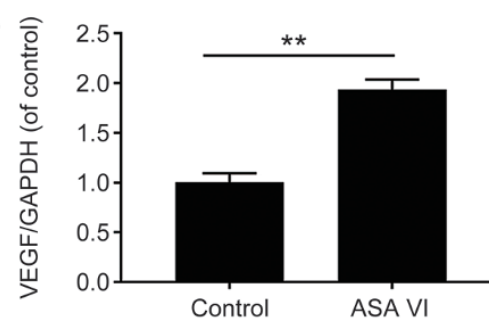

Figure 9. ASA VI accelerated vascular formation through the HIF-1 $\alpha /$ VEGF pathway. (A, B) Representative images of $\alpha$-SMA immunostaining on $d$ 7 post-operation (scale bar: $50 \mu \mathrm{m}$. Vessel formation was accelerated by ASA VI treatment; (C, D, E) Protein levels of HIF-1 $\alpha$ and VEGF in vivo after treatment with ASA VI for $7 \mathrm{~d}$. Treatment with ASA VI significantly increased the expression of HIF-1 $\alpha$ and VEGF. The densitometric analysis of all Western blot bands was normalized to the total protein or GAPDH. $n=3$ independent experiments. ${ }^{* *} P<0.01$.

regenerated tissue, ASA VI increased granulation tissue formation, collagen deposition and remodeling, which accelerated healing in full-thickness cutaneous wounds. These findings suggested that there was promising therapeutic potential of ASA VI in vascular diseases, particularly for patients with skin wounds.

\section{Acknowledgements}

This study was supported by the National Natural Science Foundation of China (81572227), the Zhejiang Provincial Natural Science Foundation (LY14H170002), the Zhejiang Undergraduate Talent Project (2017R413071), and the Wenzhou Science and Technology Bureau Project (Y20160063).

\section{Author contribution}

Cong MAO, Hua-zi XU and Cheng-gui WANG designed the research; Cheng-gui WANG and Yi-ting LOU performed the research; Min-ji TONG, Li-lian ZHANG, Zeng-jie ZHANG, Yong-zeng FENG and Shi LI collected and analyzed data; and Cheng-gui WANG and Cong MAO wrote the paper.

\section{References}

1 Eberhardt RT, Raffetto JD. Chronic venous insufficiency. Circulation 2014; 130: 333-46.

2 Valencia IC, Falabella A, Kirsner RS, Eaglstein WH. Chronic venous insufficiency and venous leg ulceration. J Am Acad Dermatol 2001; 44: 401-24.

3 Muralidhar A, Babu KS, Sankar TR, Reddanna P, Latha J. Evaluation of wound healing properties of bioactive fractions from the extract of Butea monosperma (lam) stem bark. Int J Phytomed 2011; 3: 41.

4 Hwang SH, Lee BH, Choi SH, Kim HJ, Won KJ, Lee HM, et al. Effects of gintonin on the proliferation, migration, and tube formation of human umbilical-vein endothelial cells: involvement of lysophosphatidic-acid receptors and vascular-endothelial-growth-factor signaling. J Ginseng Res 2016; 40: 325-33.

5 Hosemann W, Wigand M, Göde U, Linger F, Dunker I. Normal wound healing of the paranasal sinuses: clinical and experimental investigations. Eur Arch Otorhinolaryngol 1991; 248: 390-4.

6 Watelet JB, Bachert C, Gevaert P, Van Cauwenberge P. Wound healing of the nasal and paranasal mucosa: a review. Am J Rhinol 2002; 16: 77-84.

7 Kim BS, Pallua N, Bernhagen J, Bucala R. The macrophage migration inhibitory factor protein superfamily in obesity and wound repair. Exp Mol Med 2015; 47: e161.

8 Bates DO, Jones RO. The role of vascular endothelial growth factor in wound healing. Int J Low Extrem Wounds 2003; 2: 107-20.

9 Hwang J, Kim CW, Son KN, Han KY, Lee KH, Kleinman HK, et al. Angiogenic activity of human CC chemokine CCL15 in vitro and in vivo. FEBS Lett 2004; 570: 47-51.

10 Chou E, Suzuma I, Way KJ, Opland D, Clermont AC, Naruse K, et al. Decreased cardiac expression of vascular endothelial growth factor and its receptors in insulin-resistant and diabetic states. Circulation 2002; 105: 373-9.

11 Lerman OZ, Galiano RD, Armour M, Levine JP, Gurtner GC. Cellular dysfunction in the diabetic fibroblast: impairment in migration, vascular endothelial growth factor production, and response to hypoxia. Am J Pathol 2003; 162: 303-12.

12 Sarkar K, Fox-Talbot K, Steenbergen C, Bosch-Marcé M, Semenza GL. 
Adenoviral transfer of HIF- $1 \alpha$ enhances vascular responses to critical limb ischemia in diabetic mice. Proc Natl Acad Sci U S A 2009; 106: 18769-74.

13 Rey S, Semenza GL. Hypoxia-inducible factor-1-dependent mechanisms of vascularization and vascular remodeling. Cardiovasc Res 2010; 86: 236-42.

14 Shweiki D, Itin A, Soffer D, Keshet E. Vascular endothelial growth factor induced by hypoxia may mediate hypoxia-initiated angiogenesis. Nature 1992; 359: 843.

15 Hong WX, Hu MS, Esquivel M, Liang GY, Rennert RC, McArdle A, et al. The role of hypoxia-inducible factor in wound healing. Adv Wound Care 2014; 3: 390-9.

16 Bir SC, Pattillo CB, Pardue S, Kolluru GK, Shen X, Giordano T, et al. Nitrite anion therapy protects against chronic ischemic tissue injury in $\mathrm{db} / \mathrm{db}$ diabetic mice in a NO/VEGF-dependent manner. Diabetes 2014; 63: 270-81.

17 Yang HN, Park JS, Woo DG, Jeon SY, Park KH. Transfection of VEGF 165 genes into endothelial progenitor cells and in vivo imaging using quantum dots in an ischemia hind limb model. Biomaterials 2012; 33: 8670-84.

18 Garbern JC, Minami E, Stayton PS, Murry CE. Delivery of basic fibroblast growth factor with a $\mathrm{pH}$-responsive, injectable hydrogel to improve angiogenesis in infarcted myocardium. Biomaterials 2011; 32: 2407-16.

19 Won YW, McGinn AN, Lee M, Nam K, Bull DA, Kim SW. Posttranslational regulation of a hypoxia-responsive VEGF plasmid for the treatment of myocardial ischemia. Biomaterials 2013; 34: 6229-38.

20 Scharpfenecker M, van Dinther M, Liu Z, van Bezooijen RL, Zhao Q, Pukac L, et al. BMP-9 signals via ALK1 and inhibits bFGF-induced endothelial cell proliferation and VEGF-stimulated angiogenesis. J Cell Sci 2007; 120: 964-72.

21 Epstein SE, Kornowski R, Fuchs S, Dvorak HF. Angiogenesis therapy. Circulation 2001; 104: 115-9.

$22 \mathrm{Kim}$ YS, Cho IH, Jeong MJ, Jeong SJ, Nah SY, Cho YS, et al. Therapeutic effect of total ginseng saponin on skin wound healing. J Ginseng Res 2011; 35: 360-7.

23 Xing SS, Yang XY, Zheng T, Li WJ, Wu D, Chi JY, et al. Salidroside improves endothelial function and alleviates atherosclerosis by activating a mitochondria-related AMPK/PI3K/Akt/eNOS pathway. Vasc Pharmacol 2015; 72: 141-52.

24 Namba T. The Encyclopedia of Wakan-Yaku: traditional Sino-Japanese medicines, with color pictures, Vol I. Hoikusha Publishing Company, Osaka, Japan. 1993; 185-6.

25 Jung KY, Do JC, Son KH. Triterpene glycosides from the roots of Dipsacus asper. J Nat Prod 1993; 56: 1912-6.

26 Suh HW, Song DK, Huh SO, Son KH, Kim YH. Antinociceptive mechanisms of Dipsacus saponin $\mathrm{C}$ administered intrathecally in mice. J Ethnopharmacol 2000; 71: 211-8.

27 Yu X, Wang LN, Ma L, You R, Cui R, Ji D, et al. Akebia saponin D attenuates ibotenic acid-induced cognitive deficits and pro-apoptotic response in rats: involvement of MAPK signal pathway. Pharmacol Biochem Behav 2012; 101: 479-86.

28 Li C, Tian J, Li G, Jiang W, Xing Y, Hou J, et al. Asperosaponin VI protects cardiac myocytes from hypoxia-induced apoptosis via activation of the PI3K/Akt and CREB pathways. Eur J Pharmacol 2010; 649: 100-7.

29 Tang Y, Huang B, Sun L, Peng X, Chen X, Zou X. Ginkgolide B promotes proliferation and functional activities of bone marrowderived endothelial progenitor cells: involvement of Akt/eNOS and MAPK/p38 signaling pathways. Eur Cell Mater 2011; 21: 459-69.

30 Li C, Liu ZJ, Li G, Jiang W, Zhang G, Chen F, et al. Protective roles of Asperosaponin VI, a triterpene saponin isolated from Dipsacus asper Wall on acute myocardial infarction in rats. Eur J Pharmacol 2010; 627: $235-41$.

31 Gurtner GC, Werner S, Barrandon Y, Longaker MT. Wound repair and regeneration. Nature 2008; 453: 314-21.

32 Zeng Z, Zhu BH. Arnebin-1 promotes the angiogenesis of human umbilical vein endothelial cells and accelerates the wound healing process in diabetic rats. J Ethnopharmacol 2014; 154: 653-62.

33 Morimoto N, Yoshimura K, Niimi M, Ito T, Tada H, Teramukai S, et al. An exploratory clinical trial for combination wound therapy with a novel medical matrix and fibroblast growth factor in patients with chronic skin ulcers: a study protocol. Am J Transl Res 2012; 4: 52.

34 Lamalice L, Le Boeuf F, Huot J. Endothelial cell migration during angiogenesis. Circ Res 2007; 100: 782-94.

35 Ingber DE. Mechanical signaling and the cellular response to extracellular matrix in angiogenesis and cardiovascular physiology. Circ Res 2002; 91: 877-87.

36 Botusan IR, Sunkari VG, Savu O, Catrina AI, Grünler J, Lindberg S, et al. Stabilization of HIF-1 $\alpha$ is critical to improve wound healing in diabetic mice. Proc Natl Acad Sci U S A 2008; 105: 19426-31.

37 Chen $\mathrm{H}$, Jia $\mathrm{P}$, Kang $\mathrm{H}$, Zhang $\mathrm{H}$, Liu $\mathrm{Y}$, Yang $\mathrm{P}$, et al. Upregulating Hif- $1 \alpha$ by hydrogel nanofibrous scaffolds for rapidly recruiting angiogenesis relative cells in diabetic wound. Adv Healthc Mater 2016; 5: 907-18.

38 Leivonen SK, Häkkinen L, Liu D, Kähäri VM. Smad3 and extracellular signal-regulated kinase $1 / 2$ coordinately mediate transforming growth factor- $\beta$-induced expression of connective tissue growth factor in human fibroblasts. J Invest Dermatol 2005; 124: 1162-9.

39 Brem H, Kodra A, Golinko MS, Entero H, Stojadinovic O, Wang VM, et al. Mechanism of sustained release of vascular endothelial growth factor in accelerating experimental diabetic healing. J Invest Dermatol 2009; 129: 2275-87.

40 Werner S, Krieg T, Smola H. Keratinocyte-fibroblast interactions in wound healing. J Invest Dermatol 2007; 127: 998-1008.

41 Clark RA. Basics of cutaneous wound repair. J Dermatol Surg Oncol 1993; 19: 693-706.

42 Merkel JR, DiPaolo BR, Hallock GG, Rice DC. Type I and Type III collagen content of healing wounds in fetal and adult rats 1 . Proc Soc Exp Biol Med 1988; 187: 493-7. 